\title{
Molecular Variability of the Genomes of Capilloviruses from Apple, Japanese Pear, European Pear, and Citrus Trees
}

\author{
H. Magome, N. Yoshikawa, T. Takahashi, T. Ito, and T. Miyakawa
}

First, second, and third authors: Faculty of Agriculture, Iwate University, Ueda 3-18-8, Morioka 020, Japan; fourth author: Apple Research Center, National Institute of Fruit Tree Science, Nabeyashiki 92, Shimokuriyagawa, Morioka 020-01, Japan; fifth author: Department of Horticulture, Minamikyusyu University, Hibarigaoka, Takanabecho, Koyugun 884, Japan. Accepted for publication 10 December 1996.

\begin{abstract}
Magome, H., Yoshikawa, N., Takahashi, T., Ito, T., and Miyakawa, T. 1997. Molecular variability of the genomes of capilloviruses from apple, Japanese pear, European pear, and citrus trees. Phytopathology 87:389-396.

The 3'-terminal regions of the genomes of apple stem grooving virus (ASGV), isolated from apple, Japanese pear, and European pear plants, and citrus tatter leaf virus (CTLV), isolated from citrus plants, were amplified by reverse transcription-polymerase chain reaction. The DNA products were cloned and sequenced. The results indicated that the ASGV isolates from apple, Japanese pear, and European pear comprise at least two to four "sequence variants" that differ considerably from each other in nucleotide sequence. Comparison of the amino acid (aa) sequences of the open reading frame (ORF) 1- and 2-encoded proteins among isolates or sequence variants, including isolates of ASGV and CTLV reported previously, showed that the aa sequences of the ORF2-encoded protein (320 aa) and the putative coat protein (CP) (237 aa), which was equivalent to aa positions 1869 to 2105 of the ORF1-encoded protein of ASGV

(P-209), were highly conserved among isolates and sequence variants. Identities ranged from 92.8 to $100 \%$ for the ORF2-encoded protein among 15 isolates and sequence variants and from 92.4 to $100 \%$ for the $\mathrm{CP}$ among 21 isolates and sequence variants. On the other hand, the aa sequence identities of a variable 284-aa region (designated the V-region), equivalent to aa positions 1585 to 1868 of the ORF1-encoded protein (which also encoded the ORF2-encoded protein in another frame), were highly variable (53.2 to $99.3 \%$ ) among 15 isolates and sequence variants. The percentage of conserved V-region aa in all 15 isolates was only $20.4 \%$. Phylogenetic trees constructed from the aa sequences of the V-region, coat, and ORF2-encoded proteins showed that isolates and sequence variants were separated into several clusters, regardless of the source host plant species (apple, Japanese pear, European pear, citrus, and lily). In a tree constructed for the V-region proteins, two CTLV isolates were grouped into two clusters, each of which contained isolates and sequence variants from apple and Japanese pear. These results suggest that both CTLV from citrus and ASGV from Rosaceous plants should be considered isolates of ASGV.
\end{abstract}

Apple stem grooving capillovirus (ASGV) is the type species of the genus Capillovirus (15), which includes citrus tatter leaf virus (CTLV) $(5,17,23)$ and cherry virus A (6) and, possibly, lilac chlorotic leaf spot (3) and nandina stem pitting viruses (1). ASGV is distributed worldwide in Rosaceae fruit trees such as apple, pear, Japanese pear, apricot, and cherry $(8,16,22,24,30)$. Although ASGV usually latently infects these fruit trees, the virus causes apple topworking disease in Japan and induces decline syndrome in Mitsuba Kaido (Malus sieboldii), a rootstock of apple trees $(10,27)$.

ASGV has very flexuous filamentous particles, 600 to $700 \mathrm{~nm}$ long (10), that contain a polyadenylated, plus-sense ssRNA of $6,496 \mathrm{nt}$, excluding the $3^{\prime}$ poly(A) tail and a single $27-\mathrm{kDa}$ coat protein (CP) (31). The genome of ASGV (isolate P-209) from apple contains two overlapping open reading frames (ORFs) (29). ORF1 encodes a 241-kDa polyprotein (2,105 amino acids [aa]) containing consensus motifs of methyltransferase, papain-like protease, nucleotide triphosphate-binding helicase, RNA polymerase, and a $\mathrm{CP}$ in the $\mathrm{C}$-terminal region. The exact beginning of the $\mathrm{CP}$ in the ORF1-encoded protein has not been determined. A $36-\mathrm{kDa}$ protein (320 aa) encoded by ORF 2 may act as a movement protein (28). The genomes of two CTLV isolates from lily (L and Li-23) have been sequenced, and the nucleotide number and genome organization of these CTLV isolates are in perfect agreement with those of ASGV (P-209) (12,19). Comparisons of aa sequences show high similarities of the ORF1- $(88.2 \%)$ and ORF2-encoded

Corresponding author: N. Yoshikawa

E-mail address: yoshikawa@msv.cc.iwate-u.ac.jp

Publication no. P-1997-0204-01R

(C) 1997 The American Phytopathological Society proteins $(94.7 \%)$ between ASGV (P-209) and CTLV (Li-23). A region (aa positions 1585 to 1868) of the ORF1-encoded protein between the polymerase and CP that encoded ORF2 in another frame does not contain any known functional motifs found in plant virus genomes and shows relatively low similarity $(58.5 \%)$ between ASGV (P-209) and CTLV (Li-23) (28). In this paper, this region was designated the variable region (V-region).

Recently, we reported that ASGV (isolate V-3) obtained from a single shoot of Japanese pear contains two capilloviruses (designated V3-1 and V3-2). V3-1 is almost the same as ASGV P-209, and V3-2 is similar to CTLV from lilies with respect to the nucleotide and aa sequences of the CP and ORF2 regions (30). Although ASGV and CTLV currently are formally regarded as distinct viruses, isolates (Li-23 and L) from lily identified as CTLV should be considered isolates of ASGV. Thus, the relationship between ASGV and CTLV is not clearly defined, because the genome structure of CTLV from citrus has not yet been determined.

The aims of this study were (i) to compare the genomes of ASGV and CTLV isolated from apple, pear, lily, and citrus plants to establish the relationship of ASGV from Rosaceae fruit trees and CTLV from Citrus spp. and lily and (ii) to investigate whether in a single fruit tree the genome of an infecting capillovirus is homogenous or a heterogeneous mixture, as is the case with the V-3 isolate from Japanese pear.

\section{MATERIALS AND METHODS}

Virus isolates. The ASGV and CTLV isolates used in this study are listed in Table 1. Young leaves were collected from apple ( $M$. pumila (L.) Mill. var. domestica Schneider), Japanese pear (Pyrus serotina Rehder var. culta Rehder), and European pear (P. commu- 
nis L. var. sativa de Candolle) trees during May 1995 and, in a mortar and pestle, were ground with $0.1 \mathrm{M}$ phosphate buffer, $\mathrm{pH}$ 7.0, containing $2.5 \%$ nicotine alkaloid. The extracts were inoculated mechanically in Chenopodium quinoa Willd. and Nicotiana occidentalis Wheeler plants. Leaves of Citrus spp. trees infected with CTLV isolate OKITSU-WASE (13) or BUC-neg.No.3 (14), which had been maintained at Minamikyusyu University, Koyugun, Japan, also were ground and inoculated in C. quinoa plants. Leaves of inoculated plants with typical symptoms of ASGV or CTLV were assayed by immunoblotting with antisera against ASGV, apple chlorotic leaf spot virus (ACLSV), or apple stem pitting virus (ASPV). Plants infected with ASGV, but not with ACLSV or ASPV, were used for further experiments.

RNA extraction. Total RNAs were extracted from infected leaves of $C$. quinoa or $N$. occidentalis plants according to the method of Verwoerd et al. (26). A sample of leaf tissue $(100 \mathrm{mg})$ frozen at $-80^{\circ} \mathrm{C}$ was ground to a fine powder in a chilled mortar and pestle. The powder was mixed with $400 \mu$ of extraction buffer $(100 \mathrm{mM}$ Tris-HCl, pH 8.0, $10 \mathrm{mM}$ EDTA, $100 \mathrm{mM} \mathrm{LiCl,} \mathrm{1 \%} \mathrm{sodium} \mathrm{do-}$ decyl sulfate) and $400 \mu \mathrm{l}$ of water-saturated phenol and vortexed for $30 \mathrm{~s}$. A mixture of $400 \mu \mathrm{l}$ of chloroform/isoamyl alcohol (24:1, $\mathrm{vol} / \mathrm{vol})$ was added and vortexed for $30 \mathrm{~s}$. After centrifugation at $15,000 \times g$ for $5 \mathrm{~min}$, the aqueous phase was collected, and an equal volume of $4 \mathrm{M} \mathrm{LiCl}$ was added to precipitate total RNA. After standing overnight at $4^{\circ} \mathrm{C}$, the sample was centrifuged at $15,000 \times g$ for $10 \mathrm{~min}$ at $4^{\circ} \mathrm{C}$. The pellet was washed with $1 \mathrm{ml}$ of $70 \%$ ethanol, dried, and dissolved in $50 \mu \mathrm{l}$ of sterile distilled water.

Reverse-transcription polymerase chain reaction (RT-RCR). Several primers were designed for amplification of the 3 '-terminal region of capillovirus genomes on the basis of the genomic sequences of ASGV (P-209) and CTLV (Li-23) (Table 2). As shown in Figure 1, three primer pairs (P1, P2, and P3) were used for amplification of the ORF2 regions, and two primer pairs (P4 and $\mathrm{P} 5$ ) were used for $\mathrm{CP}$ regions. Among these primer pairs, P1, P2, and P3 for the ORF2 region were expected to anneal with both the ASGV (P-209) and CTLV (Li-23) genomes (Table 2). The primer pairs P4 and P5 were designed for specific amplification of the CP regions of ASGV and CTLV, respectively (Table 2). All DNA products from tests with P1, $\mathrm{P} 2$, and P3 were designed to have 346- and 387-bp regions overlapping those from P4 and P5, respectively. First-strand cDNA synthesis and PCR were conducted as follows: a reaction mixture (20 $\mu \mathrm{l})$ containing $1 \times$ first-strand buffer $(50 \mathrm{mM}$ Tris- $\mathrm{HCl}, \mathrm{pH} 8.3,75 \mathrm{mM}$ $\mathrm{KCl}, 3 \mathrm{mM} \mathrm{MgCl}_{2}$ ), $0.5 \mathrm{mM}$ deoxynucleotide triphosphates, 10 pmol of reverse primer (ASCT-3'(-) or ASCT-PC(-)) (Table 2 and Fig. 1), $5 \mu \mathrm{l}$ of total RNA, and 100 units of M-MLV reverse transcriptase (United States Biochemical Corp., Cleveland) was incubated at $37^{\circ} \mathrm{C}$ for $1 \mathrm{~h}$. Each PCR reaction mixture $(50 \mu \mathrm{l})$ contained $5 \mu \mathrm{l}$ of cDNA solution, $1 \times$ Taq buffer $(10 \mathrm{mM}$ Tris- $\mathrm{HCl}, \mathrm{pH} 8.3$, $50 \mathrm{mM} \mathrm{KCl}, 1.5 \mathrm{mM} \mathrm{MgCl}$ ), primer pairs (25 pmol each; Fig. 1 and Table 2), and 1.25 units of Taq DNA polymerase (Takara Shuzo Co. Ltd., Otsu, Japan). PCR was performed for 30 cycles of denaturation at $95^{\circ} \mathrm{C}$ for $30 \mathrm{~s}$; annealing at 53 to $60^{\circ} \mathrm{C}$ for 1 min; and elongation at $72^{\circ} \mathrm{C}$ for $1 \mathrm{~min}$. Annealing temperatures were $54^{\circ} \mathrm{C}$ for primer pairs $\mathrm{P} 1, \mathrm{P} 2$, and $\mathrm{P} 3 ; 60^{\circ} \mathrm{C}$ for $\mathrm{P} 4$; and $57^{\circ} \mathrm{C}$ for P5. Aliquots $(8 \mu \mathrm{l})$ of the reaction mixture were analyzed on $1 \%$ agarose gel in TAE buffer $(40 \mathrm{mM}$ Tris- $\mathrm{HCl}, \mathrm{pH} 7.4,20 \mathrm{mM}$ sodium acetate, $1 \mathrm{mM}$ EDTA). The remaining PCR products were purified by electroelution from the gels, followed by phenol extraction and ethanol precipitation. Pellets were dried and dissolved in $10 \mu \mathrm{l}$ of TE buffer (10 mM Tris-HCl, $\mathrm{pH}$ 8.0, $1 \mathrm{mM}$ EDTA).

PCR product cloning and nucleotide sequencing. The purified PCR products were ligated to pT7blue T-vector (Novagen, Madison, WI) and used to transform Escherichia coli (DH5 $\alpha)$. Several clones obtained from a given PCR product were selected, and the

TABLE 1. Apple stem grooving virus (ASGV) and citrus tatter leaf virus (CTLV) isolates and amplification of the $3^{\prime}$-terminal genome region by reverse transcription-polymerase chain reaction (RT-PCR) with several primer pairs

\begin{tabular}{|c|c|c|c|c|c|c|c|c|}
\hline \multirow[b]{3}{*}{ Virus } & \multirow[b]{3}{*}{ Isolate } & & & \multicolumn{5}{|c|}{ RT-PCR amplification primer pair ${ }^{\mathrm{a}}$} \\
\hline & & \multicolumn{2}{|c|}{ Origin } & \multicolumn{3}{|c|}{ ORF2 region } & \multicolumn{2}{|c|}{$\mathrm{CP}$ region } \\
\hline & & Host (cultivar) & Location & P1 & $\mathrm{P} 2$ & P3 & P4 & P5 \\
\hline ASGV & AAK & Apple (Akane) & Iwate University & + & + & + & + & + \\
\hline ASGV & JP3 & Japanese pear (Chojuro) & Iwate University & + & + & + & + & + \\
\hline ASGV & JP4 & Japanese pear (Nijisseiki) & Iwate University & + & + & + & + & + \\
\hline ASGV & EPBL & European pear (Bartlett) & Apple Research Center, NIFTS ${ }^{b}$ & - & + & + & + & + \\
\hline CTLV & BUC-neg.No.3 & Citrus sp. & Dep. Citricult., Kuchinotsu, NIFTS & - & + & + & + & - \\
\hline
\end{tabular}

a Primer pairs: P1 = CTLOR2ON(+) and ASCT-PC(-); P2 = CTL4635(+) and ASCT-PC(-); P3 = CTLV-1(+) and ASCT-PC(-); P4 = ASGV-ON3(+) and ASCT$3^{\prime}(-)$; and P5 $=$ CTLV-ON $(+)$ and ASCT-3' $(-)$. The sequences and locations of primers are described in Table 2 and Figure 1 . ORF2 = open reading frame 2; $\mathrm{CP}=$ coat protein. In the columns, + indicates that the expected DNA fragment size was amplified, and - indicates that the expected DNA fragment size was not amplified.

${ }^{\mathrm{b}}$ National Institute of Fruit Tree Science, Morioka, Japan.

TABLE 2. Primers used for reverse transcription-polymerase chain reaction amplification of the $3^{\prime}$-terminal regions of apple stem grooving virus (ASGV) and citrus tatter leaf virus (CTLV) genomes

\begin{tabular}{lll}
\hline Primer $^{\mathrm{a}}$ & \multicolumn{1}{c}{ Sequence $\left(5^{\prime} \text { to } 3^{\prime}\right)^{\mathrm{b}}$} & Expected primer specificities \\
\hline Forward & & \\
CTLOR2ON(+) & ${ }^{4767}$ TGGAGAAGGAATTGGGTCTG $^{4786}$ & ASGV (P-209) and CTLV (Li-23) \\
CTL4635(+) & ${ }^{4635} \mathrm{CTACAGGTTAGGTGAGAGGC}^{4654}$ & ASGV (P-209) and CTLV (Li-23) \\
CTLV-1(+) & ${ }^{4556}$ GGGCCAGGATTAAGATGATG $^{4575}$ & ASGV (P-209) and CTLV (Li-23) \\
ASGV-ON3(+) & ${ }^{5389}$ GGGCTTCACAGGCAATCAGC $^{5408}$ & ASGV (P-209) \\
CTLV-ON(+) & ${ }^{5347}$ ATTCAGCTCGTTTCTTGGAG ${ }^{5366}$ & CTLV (Li-23) \\
Reverse & & \\
ASCT-PC(-) & & ASGV (P-209) and CTLV (Li-23) \\
ASCT-3'(-) & ${ }^{5734}$ TCAGAAGTTCCTTTGCCGGG ${ }^{5715}$ & ASGV (P-209) and CTLV (Li-23) \\
\hline
\end{tabular}

a Primers were designed on the basis of the nucleotide sequences of the genomes of ASGV (isolate P-209) and CTLV (isolate Li-23).

${ }^{b}$ Indicates the nucleotide positions in the genome of ASGV (P-209). 
nucleotide sequences were determined with a Hitachi (Tokyo) 5500 DNA sequencer by the dideoxynucleotide chain-termination method (21) and Thermo Sequenase (Amersham, Tokyo). At least three independent clones for every isolate or sequence variant (Table 1; discussed below) were used to determine the nucleotide sequence of the CP or ORF2-encoded protein region. Sequence data were collected, assembled, and analyzed by GENETYX (Software Development Co., Ltd., Tokyo). Multiple alignments of aa sequences were obtained by CLUSTAL W (25). Phylogenetic trees were constructed by the neighbor-joining method (20), and the statistical significance of branch order was estimated by performing 1,000 replications of bootstrap resampling of the original alignment by CLUSTAL W (25).

\section{RESULTS}

Amplification of the $3^{\prime}$-terminal regions of capillovirus isolate genomes from apple, Japanese pear, European pear, and citrus plants. Virus isolates from apple (isolates AF38 and AAK), Japanese pear (isolates JP3 and JP4), European pear (isolates EPBL and EPLF), and citrus (isolates OKITSU-WASE and BUCneg.No.3) all induced typical symptoms of ASGV infection in inoculated $C$. quinoa plants, including epinasty, distortion, and mottle in upper leaves. The only isolate that could be distinguished from the others by the type and severity of symptoms was EPBL, which induced necrotic spots in inoculated leaves.

The 3'-terminal regions (ORF2 and CP) of the ASGV and CTLV genomes of the eight isolates described above were amplified with three primer pairs (P1, P2, and P3) for the ORF2-encoded region and two primer pairs (P4 and P5) for the CP region (Table 1 and Fig. 1). As summarized in Table 1, DNA fragments could be amplified by RT-PCR and almost all of the primer pairs for the eight isolates. We were unable to use RT-PCR and primer pair P1 to amplify the ORF2 regions of four isolates (EPBL, EPLF, OKITSUWASE, and BUC-neg.No.3), and similarly, with P5 we could not amplify the CP region of isolate BUC-neg.No.3. The sizes of the RT-PCR product for each primer pair almost agreed with those expected based on the nucleotide sequence of ASGV (P-209) and CTLV (Li-23) (968 bp for P1, 1,100 bp for P2, 1,179 bp for P3, 1,108 bp for P4, and 1,150 bp for P5).

Genomic heterogeneity of ASGV in single apple, Japanese pear, and European pear plants. We cloned the PCR products corresponding to each primer pair for isolates AF38, AAK, JP3, JP4, EPBL, EPLF, OKITSU-WASE, and BUC-neg.No.3 and de- termined their nucleotide sequences. Considerable sequence variations were found among the DNA clones obtained from a single isolate. For example, sequence analysis of three clones from a AF38 PCR product amplified by P4 or P5 indicated that three P4 DNA clones had almost identical sequences (the identities among the clones were 99.9 to $100 \%$ in 1,068 bp), and three P5 clones also had nearly identical sequences (the identities among the clones were 99.7 to $99.9 \%$ in $1,110 \mathrm{bp}$ ). However, sequence comparisons between the P4 and P5 DNA clones revealed considerable sequence variation ( 87 base substitutions per $1,068 \mathrm{bp}$, identity of $91.9 \%$ ). We refer to the different nucleotide sequences found within an isolate as "sequence variants" (e.g., two sequence variants within isolate AF38 were designated AF38-CO and AF38-3) (Table 3).

The nucleotide sequence of the ORF2 region in isolate AF38 was almost identical among clones of PCR products amplified by P1, P2, and P3 and was completely identical to the sequence of AF38-3 in overlapping regions (346 bp including primer sequences) of PCR products. We were unable to obtain clones for the ORF2 region of AF38-CO (reason unknown). In isolate JP3, sequence analysis of DNA clones generated by RT- PCR and primer P4 or P5 indicated that JP3 contained at least four sequence variants (JP3-CO, JP3-3-1, JP3-3-2, and JP3-3-3) (Table 3). The DNA clones (ORF2 region) amplified with P1, P2, and P3 all had the same sequence, which was identical to the overlapping region of sequence variant JP3-CO amplified by P5. Sequence variations among clones within an isolate were found in isolates AAK (sequence variants AAK-CO and AAK-3) from apple, JP4 (sequence variants JP4-CO, JP4-3-1, and JP4-3-2) from Japanese pear, and EPBL (sequence variants

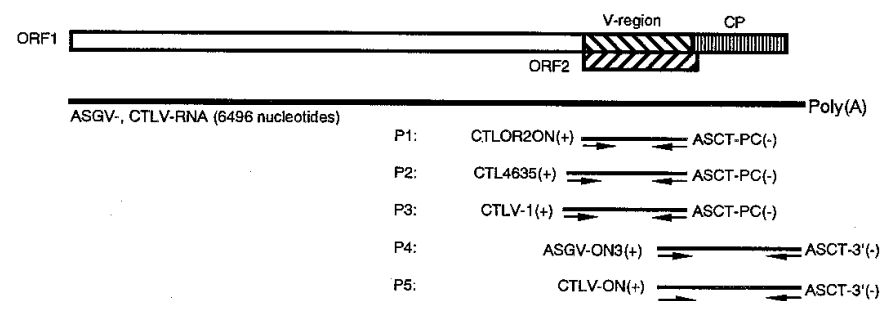

Fig. 1. Genome map and location of primers used in this study and the expected DNA products amplified by primer pairs $(\mathrm{P})$ in reverse transcriptionpolymerase chain reaction of apple stem grooving virus (ASGV) and citrus tatter leaf virus (CTLV) genomes. P1 to P5 indicate the primer pairs used for amplification of the open reading frame (ORF) 2 (P1 through P3) and coat protein $(\mathrm{CP})(\mathrm{P} 4$ and $\mathrm{P} 5)$ regions.

TABLE 3. Sequence variants found in reverse transcription-polymerase chain reaction-generated cDNA clones for isolates of apple stem grooving and citrus tatter leaf viruses

\begin{tabular}{|c|c|c|c|c|c|c|c|c|}
\hline \multirow[b]{2}{*}{ Isolate } & \multirow[b]{2}{*}{ Sequence variant } & \multicolumn{4}{|c|}{ Primer pairs for ORF2 region ${ }^{\mathrm{a}}$} & \multicolumn{3}{|c|}{ Primer pairs for $\mathrm{CP}$ region ${ }^{\mathrm{a}}$} \\
\hline & & $\mathrm{P} 1^{\mathrm{b}}$ & $\mathrm{P} 2^{\mathrm{b}}$ & $\mathrm{P} 3^{\mathrm{b}}$ & Identities $^{\mathrm{c}}$ & $\mathrm{P} 4^{\mathrm{b}}$ & $\mathrm{P} 5^{\mathrm{b}}$ & Identities $^{\mathrm{c}}$ \\
\hline \multirow[t]{2}{*}{ AF38 } & AF38-CO & $\cdots$ & $\ldots$ & $\ldots$ & & $\cdots$ & 3 & $99.7-99.9$ \\
\hline & AF38-3 & 3 & 3 & 3 & $99.7-99.8$ & 3 & $\ldots$ & $99.9-100$ \\
\hline AAK & AAK-3 & $\ldots$ & 3 & $\ldots$ & $99.7-99.8$ & 3 & $\ldots$ & 99.7 \\
\hline \multirow[t]{2}{*}{ JP3 } & JP3-CO & 3 & 3 & 3 & 100 & $\ldots$ & 3 & 100 \\
\hline & JP3-3-1 & $\ldots$ & $\ldots$ & $\ldots$ & & 4 & $\ldots$ & $99.5-100$ \\
\hline \multirow{2}{*}{ JP4 } & JP4-3-1 & 3 & $\ldots$ & $\ldots$ & $99.3-99.8$ & 3 & $\ldots$ & $99.9-100$ \\
\hline & JP4-3-2 & $\ldots$ & 3 & $\ldots$ & $99.7-99.9$ & & & \\
\hline \multirow[t]{2}{*}{ EPBL } & EPBL-CO & & 3 & 1 & $99.4-99.8$ & $\ldots$ & 3 & $99.9-100$ \\
\hline & EPBL-3 & & $\ldots$ & $\ldots$ & & 3 & $\ldots$ & 100 \\
\hline \multirow[t]{2}{*}{ EPLF } & EPLF-CO & & 3 & 3 & $99.6-99.8$ & .. & 3 & 100 \\
\hline & EPLF-3 & & $\ldots$ & $\ldots$ & & 3 & $\ldots$ & 99.6 \\
\hline
\end{tabular}

a $\mathrm{ORF} 2=$ open reading frame $2 ; \mathrm{CP}=$ coat protein.

b Number of cDNA clones sequenced; ... indicates the sequence of the sequence variant was not found among the cDNA clones.

${ }^{c}$ Percent identities of the nucleotide sequences among cDNA clones in a given sequence variant or isolate. 


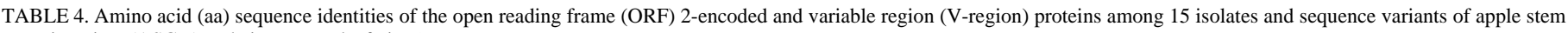
grooving virus (ASGV) and citrus tatter leaf virus ${ }^{\mathrm{a}}$

\begin{tabular}{|c|c|c|c|c|c|c|c|c|c|c|c|c|c|c|c|}
\hline & P-209 & V3-1 & $\mathrm{Li}-23$ & $\mathrm{~L}$ & V3-2 & JP3-CO & EPBL-CO & EPLF-CO & AF38-3 & AAK-CO & JP4-CO & AAK-3 & JP4-3-1 & $\begin{array}{c}\text { OKITSU- } \\
\text { WASE }\end{array}$ & $\begin{array}{c}\text { BUC- } \\
\text { neg.No.3 }\end{array}$ \\
\hline P-209 & & 99.7 & 94.7 & 94.7 & 94.7 & 94.7 & 95.9 & 96.3 & 95.9 & 95.6 & 95.3 & 93.4 & 94.1 & 96.3 & 95.0 \\
\hline V3-1 & 99.3 & & 95.0 & 95.0 & 95.0 & 95.0 & 96.3 & 96.6 & 96.3 & 95.9 & 95.6 & 93.8 & 94.4 & 96.6 & 95.3 \\
\hline $\mathrm{Li}-23$ & 58.5 & 58.5 & & 98.8 & 97.5 & 97.5 & 97.8 & 97.5 & 97.2 & 96.9 & 96.6 & 93.4 & 94.1 & 96.6 & 95.9 \\
\hline $\mathrm{L}$ & 56.7 & 56.7 & 97.5 & & 97.5 & 97.5 & 97.8 & 97.5 & 97.2 & 96.9 & 96.6 & 93.4 & 94.1 & 96.6 & 95.9 \\
\hline V3-2 & 61.3 & 61.6 & 85.6 & 83.8 & & 100 & 97.8 & 97.5 & 97.5 & 97.2 & 96.9 & 93.4 & 94.4 & 96.3 & 95.6 \\
\hline JP3-CO & 61.6 & 62.0 & 85.2 & 83.5 & 98.9 & & 97.8 & 97.5 & 97.5 & 97.2 & 96.9 & 93.4 & 94.4 & 96.3 & 95.6 \\
\hline EPBL-CO & 60.2 & 60.2 & 87.3 & 85.6 & 86.3 & 85.9 & & 99.7 & 97.8 & 97.5 & 97.2 & 94.1 & 94.7 & 97.2 & 97.2 \\
\hline EPLF-CO & 60.2 & 60.2 & 88.0 & 86.6 & 87.0 & 86.6 & 98.6 & & 97.5 & 97.2 & 96.9 & 93.8 & 94.4 & 96.9 & 96.9 \\
\hline AF38-3 & 53.2 & 53.9 & 58.5 & 58.1 & 58.5 & 58.1 & 55.3 & 54.6 & & 99.4 & 98.8 & 94.1 & 95.3 & 97.2 & 96.9 \\
\hline AAK-CO & 55.3 & 56.0 & 59.2 & 58.1 & 59.9 & 59.5 & 56.7 & 56.0 & 97.9 & & 98.8 & 93.8 & 95.0 & 97.5 & 97.2 \\
\hline JP4-CO & 54.6 & 55.3 & 60.9 & 60.6 & 60.6 & 60.2 & 57.7 & 57.0 & 93.7 & 93.7 & & 94.1 & 95.0 & 96.6 & 96.9 \\
\hline AAK-3 & 58.1 & 58.8 & 55.3 & 54.9 & 54.6 & 55.3 & 54.6 & 55.3 & 56.0 & 54.9 & 55.3 & & 97.8 & 94.7 & 92.8 \\
\hline JP4-3-1 & 58.5 & 59.2 & 54.9 & 53.9 & 54.2 & 54.9 & 54.2 & 54.9 & 57.0 & 56.0 & 56.3 & 90.8 & & 94.7 & 94.1 \\
\hline OKITSU-WASE & 82.4 & 83.1 & 54.6 & 53.2 & 58.1 & 57.7 & 58.5 & 58.5 & 56.0 & 58.1 & 56.3 & 59.5 & 60.6 & & 95.9 \\
\hline BUC-neg.No.3 & 54.6 & 55.3 & 56.0 & 54.9 & 56.0 & 54.9 & 54.2 & 53.5 & 80.6 & 81.3 & 79.2 & 56.0 & 56.7 & 55.3 & \\
\hline
\end{tabular}

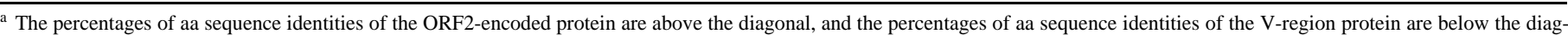
onal. For the V-region, aa sequence equivalent to aa positions 1585 to 1868 of the ORF1 protein of ASGV (isolate P-209) are compared. Database accession numbers for P-209, Li-23, and $\mathrm{L}$ are D14995, D16368, and D16681, respectively.

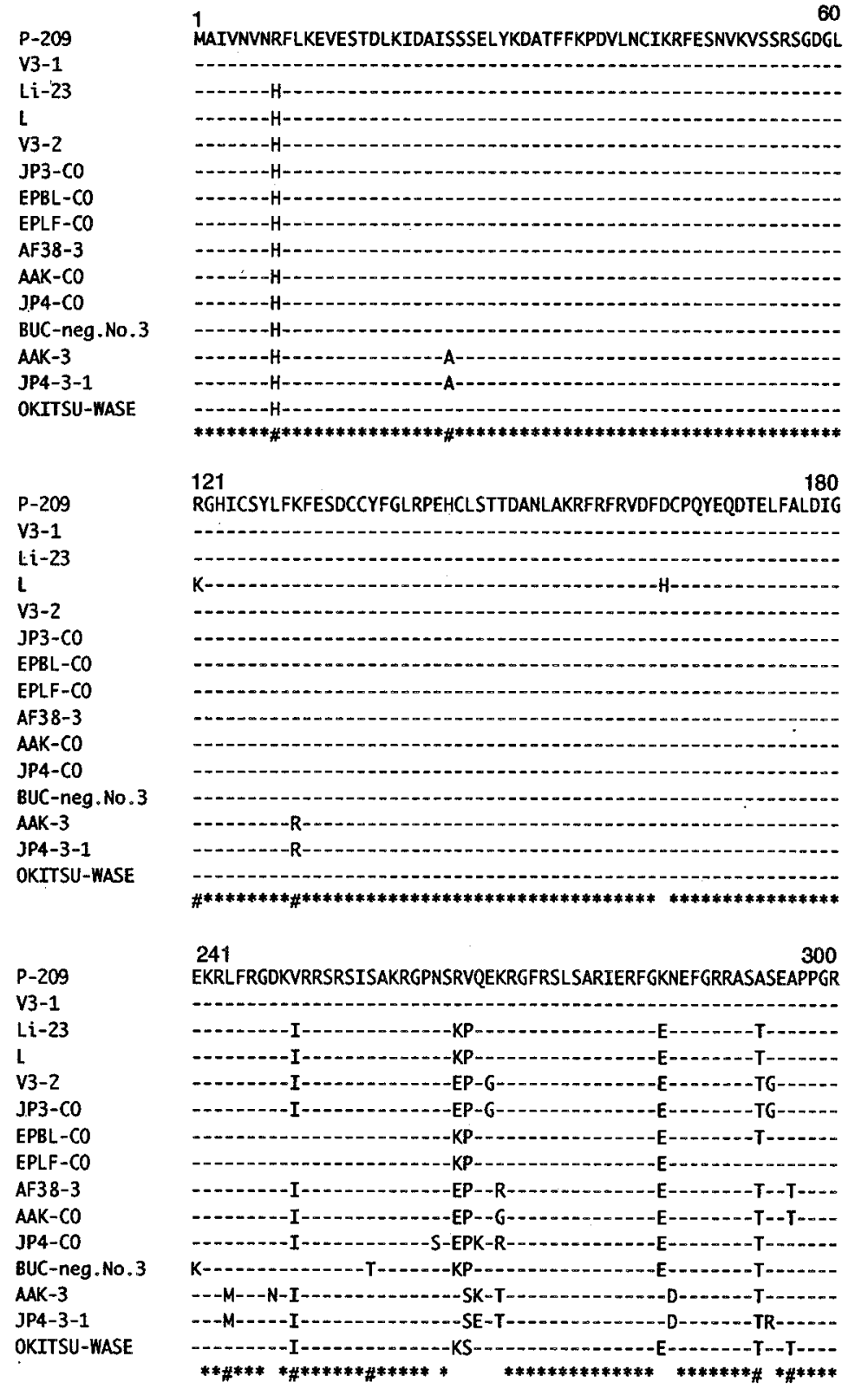

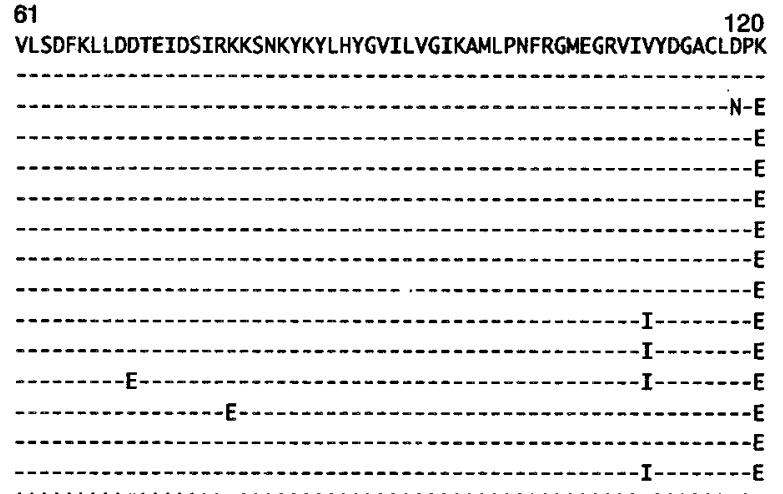

$* * * * * * * * * \# * * * * * * * * * * * * * * * * * * * * * * * * * * * * * * * * * * * * * * * * * * * * * * *$

181

VAYRCVNSARFLETKTGDSGWASQAISGCEALKFNEEIKMAILDRRSPLFLEEGAPNVHI

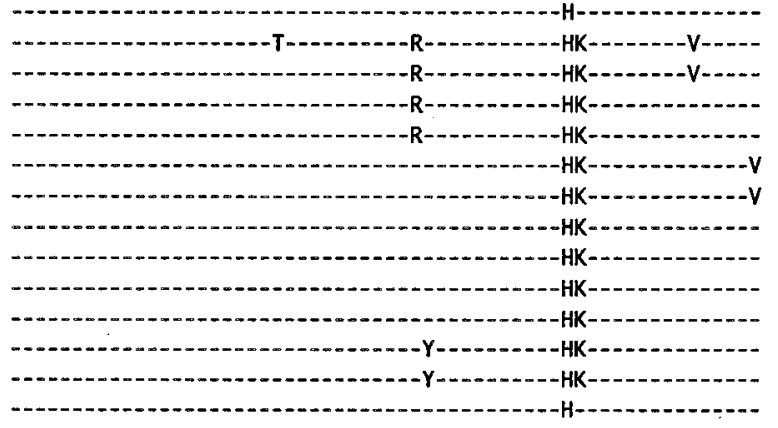

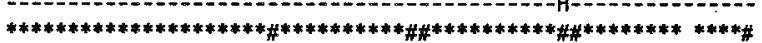

\begin{tabular}{|c|c|}
\hline \multirow{2}{*}{\multicolumn{2}{|c|}{$\begin{array}{l}301 \\
\text { SISMEDSHRP }\end{array}$}} \\
\hline & \\
\hline$-V-L--T Y--$ & \\
\hline$-V-L=-T Y-\cdots$ & \\
\hline$-V-L--A Y-S-$ & \\
\hline$-V-L--A Y-S---$ & \\
\hline$-V-L--A Y-\cdots$ & \\
\hline -V-L--AY---- & \\
\hline$-V-L-\ldots$ & \\
\hline$-V-L-\cdots$ & \\
\hline -V-L- & \\
\hline$-V-L-N-\cdots-C-N-\cdots$ & \\
\hline$---V--P Y-----1$ & \\
\hline$-V-V--P-\cdots---N-$ & \\
\hline$*_{* * \# *} \quad * \quad * * * \# *$ & \\
\hline
\end{tabular}

Fig. 2. Alignment of the amino acid (aa) sequences of the open reading frame 2-encoded protein ( $320 \mathrm{aa}$ ) of isolates and sequence variants of apple stem grooving virus (ASGV) and citrus tatter leaf virus. Amino acids that differ from those of ASGV isolate P-209 are shown below the P-209 sequence. Asterisks indicate identical aa in all isolates and sequence variants, and pound signs indicate conservative aa exchanges. 
EPBL-CO and EPBL-3) and EPLF (sequence variants EPLF-CO and EPLF-3) from European Pear (Table 3). In two CTLV isolates (OKITSU-WASE and BUC-neg.No.3) from citrus trees, sequence analysis showed that the DNA clones amplified by any primer pair for either isolate had identical nucleotide sequences.

The nucleotide sequence identities among isolates or sequence variants were 82.1 to $99.8 \%$ in the ORF2 regions (equivalent to nucleotide positions 4788 to 5714 of the P-209 genome) and 89.1 to $99.9 \%$ in the $\mathrm{CP}$ regions (nucleotide positions 5715 to 6476 of the $\mathrm{P}-209$ genome).

Analysis and comparisons of the aa sequences encoded by ORF1 and ORF2 among isolates and sequence variants of ASGV and CTLV. Comparisons of the 3 '-terminal regions of isolates and sequence variants among corresponding regions of ASGV (P-209) and CTLV (Li-23) showed that the coding regions of all isolates and sequence variants were completely consistent with those of P209 and Li-23, without deletion or insertion of bases. Variations on the nucleotide number were found only in the 3 -noncoding region, i.e., sequence variants JP3-3-3 and JP4-3-1 had one base insertion and JP3-3-1 and OKITSU-WASE had two base insertions compared to P-209 and Li-23.

The aa sequences of the ORF2-encoded protein (320 aa), a putative CP region (237 aa, corresponding to aa positions 1869 to 2105 of P-209), and the V-region (284 aa, corresponding to aa positions
1585 to 1868 of P-209) in the ORF1-encoded protein were compared among isolates and sequence variants analyzed in this study and have been reported previously $(18,28-30)$ (Table 4, and Figs. 2 through 4). Amino acid sequences of the ORF2 and CP regions were highly conserved among isolates and sequence variants, and the identities among them ranged from 92.8 to $100 \%$ for the ORF2encoded (Table 4) and from 92.4 to $100 \%$ for the CP proteins. The percentage of conserved aa was $87.2 \%$ (279 aa per 320 aa) for ORF2 in all 15 isolates and sequence variants (Fig. 2). In the case of CPs, the percentage of conserved aa was $87.3 \%$ (207 aa per 237 aa) in all 21 isolates and sequence variants (Fig. 3). In contrast, the aa sequences of the V-region were highly variable (53.2 to $99.3 \%$ ) among isolates and sequence variants (Table 4), and the percentage of conserved aa in all 15 isolates or sequence variants was only $20.4 \%$ (58 aa per 284 aa) (Fig. 4).

Phylogenetic analysis of ASGV and CTLV from apple, Japanese pear, European pear, citrus, and lily plants. We analyzed phylogenetic relationships among isolates and sequence variants by multiple alignments of the aa sequences of a V-region protein, a putative $\mathrm{CP}$, and the ORF2-encoded protein. Phylogenetic analysis of the aa sequences of V-regions (284 aa) showed that isolates and sequence variants were separated into four large clusters (I, II, III, and IV), regardless of the host plants from which they were iso-
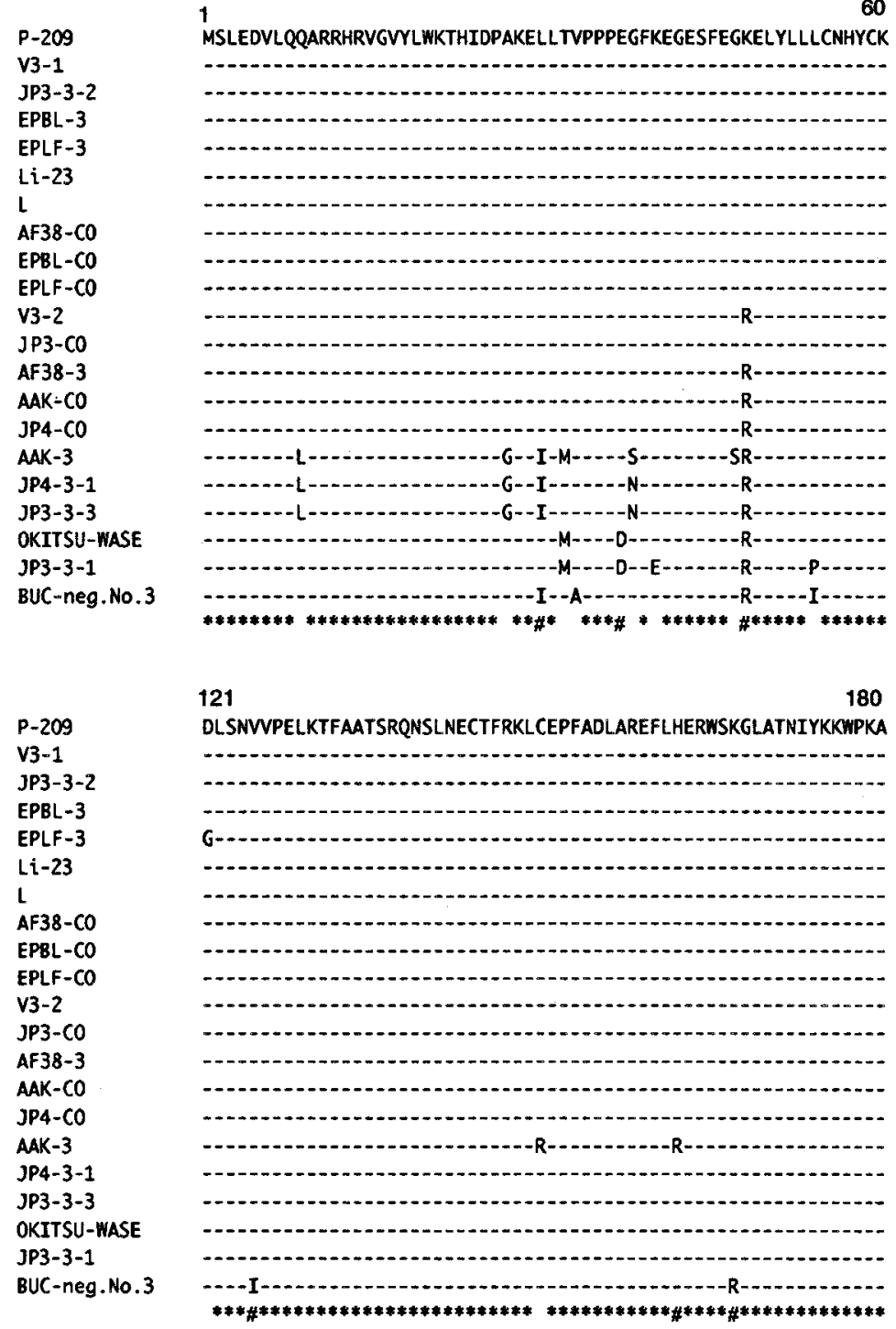

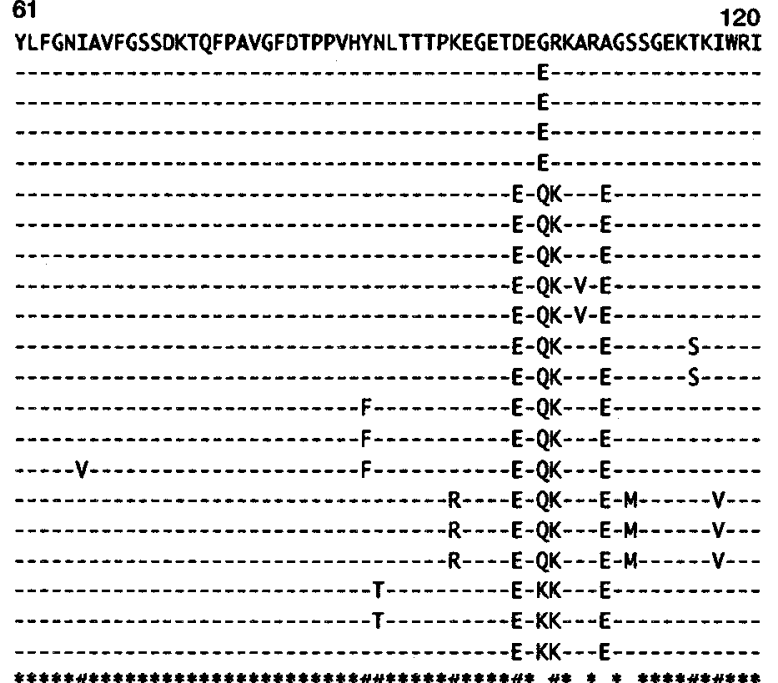

181 FEKSPWVAFDFATGLKMNRLIPDEKQVIDRMTKRLFRTEGQKGVFEAGSESNLELEG

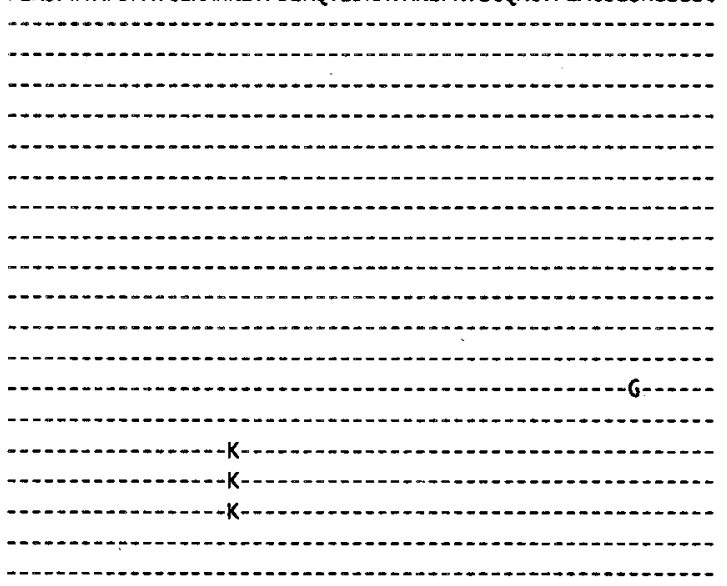

*****************************8**************************

Fig. 3. Alignment of the amino acid (aa) sequences of the putative coat protein (CP) region ( 237 aa) of the open reading frame (ORF) 1-encoded protein of isolates and sequence variants of apple stem grooving virus (ASGV) and citrus tatter leaf virus. The putative CP region is equivalent to aa positions 1869 to 2105 of the ASGV isolate P-209 ORF1-encoded protein. Amino acids that differ from those of P-209 are shown below the P-209 sequence. Asterisks indicate identical aa in all isolates and sequence variants, and pound signs indicate conservative aa exchanges. 
lated (Fig. 5A). Phylogenetic trees constructed from the aa sequences of $\mathrm{CP}$ and $\mathrm{ORF} 2$-encoded proteins also consisted of several clusters in which isolates and sequence variants in clusters I, III, and IV were nearly consistent with those in clusters I, III, and IV constructed by the V-region (Fig. 5B and C). Two isolates from citrus (OKITSUWASE and BUC-neg.No.3), which were included in clusters I and III, respectively, in a tree for the V-region, were not contained in any clusters in trees for the CP or ORF2-encoded protein.

\section{DISCUSSION}

The results of nucleotide sequence analyses of the RT-PCRgenerated ASGV cDNA clones indicated that all ASGV isolates from apple, Japanese pear, and European pear contain at least two to four sequence variants that differ considerably from each other in nucleotide sequence. It is probably a universal phenomenon that the virus genome that exists in a single virus-infected plant is heterogeneous, i.e., a mixture of sequence variants. Similar results were reported recently for ASGV isolate V-3 from Japanese pear
(30) and for ACLSV from a French peach plant, in which isolate LS16 of ACLSV was composed of a mixture of three widely divergent variants (4). One question we encountered in this study concerned the specificities of primer pairs. The DNA clones generated by any primer pairs for the $\mathrm{ORF} 2$ regions (P1, P2, and $\mathrm{P} 3$ ) all had the same sequence as that of variant AF38-3 but not of AF38-CO in isolate AF38, and all had the sequence of JP3-CO but not of variants JP3-3-1, JP3-3-2, and JP3-3-3 in isolate JP3.

Both ASGV and ACLSV are believed to not be transmitted by vectors, and therefore, virus spread does not occur easily in fields without graft transmission $(9,10)$. Based on the assumption that several sequence variants occur in a single tree, we speculate that mutations (nucleotide substitutions) successively accumulated in the preexisting genome, or each sequence variant was brought to a single tree from a rootstock or a scion originally infected by that variant. On the other hand, genomes from samples infected with isolates P-209, Li-23, OKITSU-WASE, and BUC-neg.No.3 appeared to be homogenous. P-209 was isolated originally from apple more than 20 years ago (27), and Li-23 was reported from lily in 1978 (5).

\begin{tabular}{|c|c|}
\hline P-209 & WLSSTSTASSRRSNLQTSKLMLSRPQSFTRMQPFSNQTCLIASK \\
\hline V3-1 & $x^{-2}$ \\
\hline OKITSU-WASE & $---M--T---K L--R---n-\ldots$ \\
\hline Li-23 & $-\mathrm{R}--\mathrm{M}--\mathrm{I}-----\mathrm{SQ}---\mathrm{R}-\mathrm{TQ}-\mathrm{H}--\mathrm{N}--\mathrm{K}-\cdots----\mathrm{M}-\mathrm{S}-\mathrm{V}-$ \\
\hline $\mathbf{l}$ & $-R--M--I-\cdots---S Q---R-T Q-H--N--K-\cdots--S R M-S-V-$ \\
\hline v3-2 & $-Q--M--I-\cdots-S Q--L R-T--H-\cdots--K----S R M-S-V-$ \\
\hline JP3-CO & $-Q--M--I-----S Q--L R-T--H--\cdot--K-\cdots--S R M-S-V-$ \\
\hline EPBL-CO & $-R--M--I----S Q--L R-T Q-H-R N--K-\cdots-S-S R M-S-V L$ \\
\hline EPLF-CO & $-R--M--I-\cdots-S Q--L R-T Q-H-R N--K-\cdots-S R M-S-V L$ \\
\hline AF38-3 & $-Q----I T-----S Q L--R--R-L-L---K--L S-S-M-S T V-$ \\
\hline AAK-CO & $-Q----I T----S Q L--R--R-L-L---K--L S-S-M-S T V-$ \\
\hline JP4-CO & $-Q---I T-\cdots--S Q L--R--Q-L-L---K--L S-S-M-S T V-$ \\
\hline BUC-neg.No.3 & $---L--I T--K---Q L I-R S-Q-L-L---K--L S---M-S T V-$ \\
\hline AAK-3 & $-R--M--T--K---Q-I----P--L N S I K-\cdots-L S R M Y S---1$ \\
\hline \multirow[t]{3}{*}{$3 P 4-3-1$} & $-Q L-M--T--K-L-Q-I \cdots-P---L N-I K----S-M Y S--$ \\
\hline & $* \quad * \quad * * \# \# \quad \# \quad * * \quad \# * * \quad \#$ \\
\hline & 121 \\
\hline P-209 & EATFARIFSSLSLTVATLVSGQSTVCLPQTQIWPKGLDFWTLI \\
\hline V3-1 & 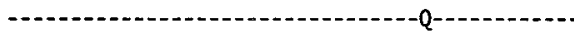 \\
\hline OKITSU & 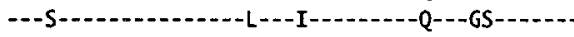 \\
\hline Li-23 & $--I Y---C L-----A V-S-L D L N-A Y P--M P T-R R D S-\cdots---T$ \\
\hline $\mathbf{L}$ & K-IY---CL-----AV-S-LDLN-AYP--MPT-RRDS----FT \\
\hline v3-2. & $---Y V H-C L-\cdots--A V-S-L D L N--Y P-R M P T-R-D S \cdots-\cdots$ \\
\hline $\mathrm{JP3}-\mathrm{CO}$ & $---Y V H-C L-\cdots--A V-S-L D L N--Y P-R M P T-R-D S--\cdots-T$ \\
\hline EPBL-CO & $--I Y-H-C L-\cdots---A Y-S-L-L N-A Y P--M P T-R R D S \cdots--I--$ \\
\hline EPLF-CO & $--I Y-H-C L-\infty--A Y-S-L D L N-A Y P--M P T-R R D S-\cdots I S-$ \\
\hline AF38-3 & GG-SVH-C---IAVI-D-DLNI-FQQR-PT-QR-SG-G-I- \\
\hline AAK-CO & G--SVH-C-----IAV--D-DLNI-FQQR-PT-QR-SG-G-I-T \\
\hline JP4-CO & G--S-H-C----IAV--D-DLNI-FQQR-PT-QR-SG-G-I-T \\
\hline BUC-neg & G--S-PTC-N---IA---DLDLNI-FQQR-P--QR-SG-E-I-T \\
\hline AAK-3 & -VIYVPTY-D---IAV--D-DRNI-Y-QLML--Q--SGSE---T \\
\hline \multirow[t]{3}{*}{ JP4-3-1 } & -VIYVPTY-G---IAV--D-D-NIA--QLML--Q--SGSE-I- \\
\hline & $* *$ \\
\hline & 241 \\
\hline P-209 & KRDCSEVTRLEGHAQFPLKGGQTQGCKKREDLGPSRLELKDLEK \\
\hline v3-1 & - n- \\
\hline OKITSU- & RK-Y--A-K--RVL-L----IRNRR----- - Q - - \\
\hline Li -23 & 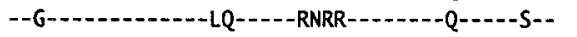 \\
\hline $\mathbf{L}$ & 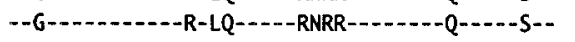 \\
\hline V3-2 & 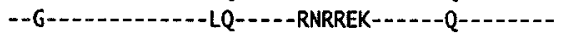 \\
\hline $\mathrm{JP3}-\mathrm{CO}$ & $--G---------L Q----$ RNRREK- \\
\hline$E P B L-C O$ & $--G=-\ldots-L_{-1}$ \\
\hline EPLF-CO & 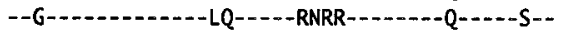 \\
\hline AF $38-3$ & 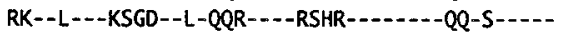 \\
\hline AAK-CO & 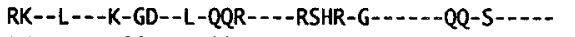 \\
\hline $\mathrm{JP4}-\mathrm{CO}$ & RK--L----SGD--L-QQR---ARSQR-G-----QQ-S- - - \\
\hline BUC-neg. No. 3 & -K--L---KSGD--PLQQRE-- -SHR- \\
\hline AAK-3 & $-K E--G--S-D R V L S L P \cdots-\cdots-Q----Q Q---S G-$ \\
\hline \multirow[t]{2}{*}{ JP4-3-1 } & $-K E--G \cdots-S G-R V L S L P \cdots-\cdots--\cdots-\cdots,-\cdots$ \\
\hline & $\# \# \quad * \quad \# \quad \# \quad \# * * \# \quad \# \quad * * * * * * \# * * *$ \\
\hline
\end{tabular}

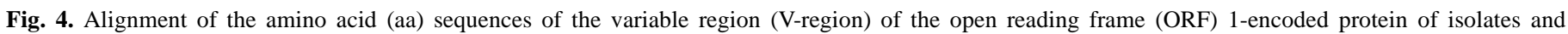

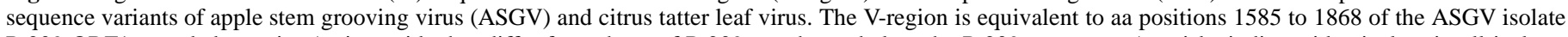

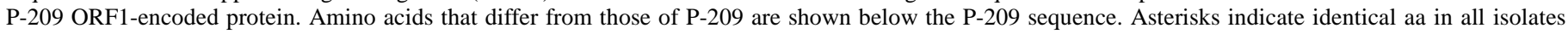
and sequence variants, and pound signs indicate conservative aa exchanges.

60 SCLISNCLMTPKLIQSGRKATSTNTYTMESSWLGSKQCCQTLEAWKGESLYMMEPAWIRK F--T--YS-D.-$--Q--S----L-S T---K R----S-C I T--F-L E------S-V--E G--C-T--V L-\cdots$ --Q--S----L-ST--EKR----S-CIT--F-LE----- -S-V--EG--C-T--VL----Q--S----L-ST----R-I--S--I---F-LE-------S-V--EG--C-----L----Q--S----L-ST----R----S--I---F-LE-------S-V--EG--C--.--L-.-$--Q--S----L-S T---K R=---S-C I---F-L E L-\cdots---S----E G--C-----L--R$ $--Q--S-.--L-S T---K R----S-C I---F-L E L-----S----E G--C----L--R$ C--T--Y------TRFEKRV---S-C-T--Y-LE--L---I-GE--E-----TG-V-TQC--T--Y------TRF-KRV---S-C-T--Y-LE--L---I-GE--E--..--G-V-TQC--T--Y-...-TRFEK-V---S-C-T--Y-LE--L---SSGE--E-.---.G-V-TQC--T--S--K---T-F-KR-I--S-CI----LEL-P-Y-I-GG--.-.-T---V-TQC-PT-S----Q--TPLE-R--.--ICI---FLLA-----P--GE---GL---TV-V-TQ-

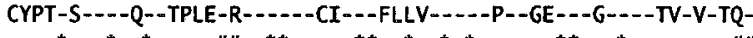
181 LHTDASTLQGFWKPKLAIQDGLHRQSAAVKHLNSMRKSRWPSWIADPRCFWKKVHQTCTL WP--VLIQLVS-R-R-ET-G-PR-LLV--R-SDL-K:-LK-QF--ISLHY--R--F-MFIWP--VLIQPAS-R-R-ET-G-PR-LLV--R-SDL-K-LK-QF--ISLHY--R--F-MFIWL----IQLVS-R-R-ET-G-PR-LL--AR-SD--K--K-QF--TSLH---R--L-MY-WL-G--IQLVS-R-R-ET-G-PR-LL --AR-SD--K--K-QF--TS-H---R--L-MY-WP-..-IQLVS-R-R-E--G-PR-LL-D-R-S---KR---R---ISLH---R--L-MYMWP---IQLVS-R-R-E--G-PR-LL---R-S---KR---R---ISLH---R--L-MYM-LI-V-IQ--SL--R-V--G-P--R-VD-R---L-K--K--F--TNLH-- -R----M---LI-V-IQ--SL - -R-V--G-P--R-VD-R---L-K--K--F--TNLH---R----M---LI-V-IQ--SL--R-V--G-P--R-VD-R-S-L-K-LK--F--TNLH-- -R--.-M--. -L--VLIR-D-L--R-V--G-P--R-VD-R-SSL-K--K-L---TNLH---R----M---

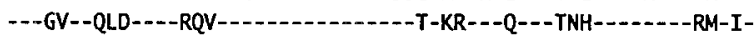
S--GV--QLDS---RQV-.........--T-KR---Q---TNH-......-RM-I-

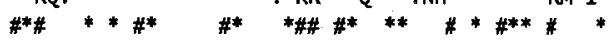


Since then, these viruses have been propagated in $C$. quinoa plants by successive mechanical inoculations. Citrus isolates OKITSUWASE (13) and BUC-neg.No.3 (14) were reported in 1976 and 1988, respectively, and since then have been maintained in citrus plants under greenhouse conditions. Although we do not know whether these isolates originally were composed of several sequence variants, serial passages of these isolates in indicator plants may have resulted in the predominance of a specific sequence variant due to selective multiplication (2). For example, in isolate V-3, which is composed of two sequence variants (V3-1 and V3-2) (30), we could amplify the DNA fragments of both sequence variants from freeze-dried $C$. quinoa samples stored at the National Insti- tute of Fruit Tree Science, Tsukuba, Japan, which originally supplied the isolate we used. However, it was difficult to amplify the DNA fragment of V3-2 from leaf samples maintained by successive passages in C. quinoa plants (N. Yoshikawa, unpublished data).

Analysis of aa sequences of the ORF1- and ORF2-encoded proteins showed that the $\mathrm{CP}$ and the ORF2-encoded protein were highly conserved among isolates or sequence variants. The ORF2encoded protein is thought to be a movement protein (28) and, therefore, to play a vital role in the infection process. Amino acid substitutions in the ORF2-encoded protein among isolates or sequence variants mainly occurred in the $\mathrm{C}$-terminal regions that overlap the $\mathrm{N}$-terminal region of the $\mathrm{CP}$ encoded by ORF1. This

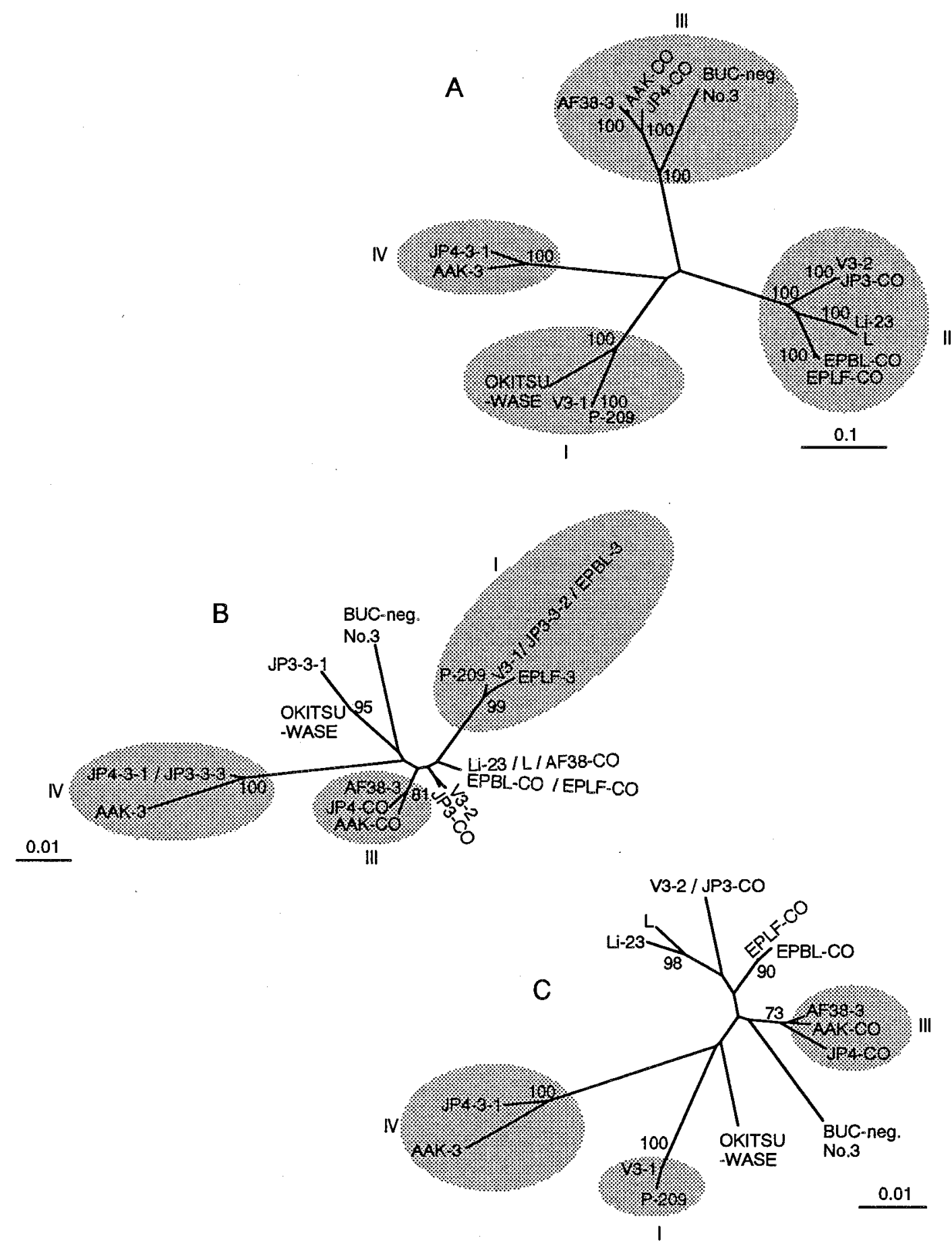

Fig. 5. Phylogenetic trees for A, the variable region (V-region) (284 amino acids [aa]) among 15 isolates and sequence variants; $\mathbf{B}$, the coat protein region (237 aa) among 21 isolates and sequence variants; and $\mathbf{C}$, the open reading frame 2-encoded protein region ( 320 aa) among 15 isolates and sequence variants of apple stem grooving and citrus tatter leaf viruses. Trees were constructed by the neighbor-joining method, with 1,000 bootstraps. The number beside each node indicates the percentage $(>70 \%)$ of bootstrap replicates. The scale bars represent the number of aa replacements per site. Four large clusters (I through IV) in the tree for the V-region (A) are shaded. Clusters in $\mathbf{B}$ and $\mathbf{C}$, which are consistent with those in $\mathbf{A}$, also are shaded and numbered. 
indicates that the conservation of the aa sequence of the $\mathrm{CP}$ is greater than that of the ORF2-encoded protein. In contrast, the aa sequences of the V-region, overlapping ORF2 in another frame, showed considerable variability among isolates and sequence variants (53.2 to $99.3 \%$ among isolates and sequence variants). Although the same nucleotide sequence region corresponds to the ORF2encoded and V-region proteins, aa substitutions of the V-region span the entire region, and the conserved aa are only $20.4 \%$ (58 aa per $284 \mathrm{aa})$ in 15 isolates and sequence variants. The clear differnce in the evolution of two proteins encoded by the same coding region is reported for ORFs 4 and 5 of tomato bushy stunt virus strains (11). The presence of the V-region is one of the characterstics of capillovirus genome organization. We do not know the function of the V-region, because this region does not have any known functional motifs found in plant viruses $(18,28,29)$. In spite of low conservation of the V-region, the fact that there is not a stop codon in all isolates and sequence variants suggests that the V-region may have a function.

Initially, we expected that isolates and sequence variants from the same fruit tree hosts might be related phylogenetically to each other. However, phylogenetic analysis in any of the phylogenetic trees constructed by multiple alignments of V-region protein, $\mathrm{CP}$, and ORF2-encoded protein revealed no phylogenetic correlation between isolates and sequence variants in each cluster and the species of fruit tree hosts from which they were isolated originally. It is reasonable to think that a phylogenetic tree constructed by V-region analysis reflects the evolutionary distance among isolates and sequence variants more exactly than those constructed from $\mathrm{CP}$ or ORF2-encoded protein analyses, because the aa sequences of V-regions show more overall divergence than those from CP and ORF2-encoded regions. Therefore, the V-region has not undergone severe evolutionary constraint. The tree constructed by V-region analysis is clearly divided into four large clusters, regardless of the hosts from which they were isolated. Cluster I consists of two isolates (P-209 and OKITSU-WASE) and a sequence variant (V3-1) in which each isolate was isolated from different fruit trees (apple, Japanese pear, and citrus). Clusters II, III, and IV also are composed of isolates and sequence variants from more than two species. Citrus and Rosaceae fruit trees are cultivated in clearly separated locations. Therefore, it is interesting that isolates OKITSU-WASE and BUC-neg.No.3 from citrus plants are grouped into different clusters (I and III) that also include isolates and sequence variants from apple and pear plants.

ASGV and CTLV currently are regarded as distinct viruses, although CTLV from lily is not distinguished from ASGV from apple based on biological and serological properties or genome organization $(5,7,17,19,28,29)$. The current study provides evidence that CTLV from citrus plants also cannot be distinguished based on the nucleotide sequence of ASGV from Rosaceae fruit trees. This research supports the proposal that CTLV be regarded as an isolate of ASGV.

\section{ACKNOWLEDGMENTS}

This study was funded in part by a grant-in-aid from the Ministry of Education, Science and Culture, Japan. We thank R. H. Converse for his critical reading of the manuscript.

\section{LITERATURE CITED}

1. Ahmed, N. A., Christie, S. R., and Zettler, F. W. 1983. Identification and partial characterization of a closterovirus infecting Nandina domestica. Phytopathology 73:470-475.

2. Aldaoud, R., Dawson, W. O., and Jones, G. E. 1989. Rapid, random evolution of the genetic structure of replicating tobacco mosaic virus populations. Intervirology 30:227-233.

3. Brunt, A. A. 1979. Lilac chlorotic leafspot virus. CMI/AAB Descriptions of Plant Viruses No. 202.

4. Candresse, T., Lanneau, M., Revers, F., Macquaire, G., German, S., Dunez, J., Grasseau, N., and Malinovsky, T. 1995. An immunocapture PCR assay adapted to the detection and the analysis of the molecular variability of apple chlorotic leaf spot virus. Acta Hortic. 386:136-147.

5. Inouye, N., Maeda, T., and Mitsuhata, K. 1979. Citrus tatter leaf virus isolated from lily. Ann. Phytopathol. Soc. Jpn. 45:712-720.

6. Jelkmann, W. 1995. Cherry virus A: cDNA cloning of dsRNA, nucleotide sequence analysis and serology reveal a new plant capillovirus in sweet cherry. J. Gen. Virol. 76:2015-2024.

7. Kawai, A., Kobayashi, T., Tsukamoto, T., Dai, K., Kimishima, E., Kimura, S., and Goto, M. 1991. Production of monoclonal antibodies against citrus tatter leaf virus. Res. Bull. Plant Prot. Ser. Jpn. 27:55-60.

8. Kinard, G. R., Scott, S. W., and Barnett, O. W. 1996. Detection of apple chlorotic leaf spot and apple stem grooving viruses using RT-PCR. Plant Dis. 80:616-621.

9. Lister, R. M. 1970. Apple chlorotic leaf spot virus. CMI/AAB Descriptions of Plant Viruses, No. 30.

10. Lister, R. M. 1970. Apple stem grooving virus. CMI/AAB Descriptions of Plant Viruses No. 31.

11. Luis-Arteaga, M., Rodríguez-Cerezo, E., Fraile, A., Sáez, E., and GarcíaArenal, F. 1996. Different tomato bushy stunt virus strains that cause disease outbreaks in solanaceous crops in Spain. Phytopathology 86:535-542.

12. Magome, H., Yoshikawa, N., and Takahashi, T. 1994. Nucleotide sequence of citrus tatter leaf virus (isolate Li-23) genome. Ann. Phytopathol. Soc. Jpn. 60:762-763. (Abstr. in Japanese).

13. Miyakawa, T., and Matsui, C. 1976. A bud-union abnormality of satsuma mandarin on Poncirus trifoliata rootstock in Japan. Pages 125-131 in: Proc. 7th Conf. IOCV. IOCV, Riverside, CA.

14. Miyakawa, T., and Tshuji, M. 1988. The association of tatterleaf virus with buduinon crease of trees on trifoliate orange rootstock. Pages 360354 in: Proc. 10th Conf. IOCV. IOCV, Riverside, CA.

15. Murphy, F. A., Fauquet, C. M., Bishop, D. H. L., Ghabrial, S. A., Jarvis, A. W., Martelli, G. P., Mayo, M. A., and Summers, M. D., eds. 1995. Virus Taxonomy: 6th Report of the International Committee on Taxonomy of Viruses. Arch. Virol. Suppl. 10.

16. Németh, M. 1986. Virus, Mycoplasma and Rickettsia Diseases of Fruit Trees. Académiai Kiadó, Budapest.

17. Nishio, T., Kawai, A., Takahashi, T., Namba, S., and Yamashita, S. 1989. Purification and properties of citrus tatter leaf virus. Ann. Phytopathol. Soc. Jpn. 55:254-258.

18. Ohira, K., Ito, T., Kawai, A., Namba, S., Kusumi, T., and Tsuchizaki, T. 1994. Nucleotide sequence of the $3^{\prime}$-terminal region of citrus tatter leaf virus RNA. Virus Genes 8:169-172.

19. Ohira, K., Namba, S., Rozanov, M., Kusumi, T., and Tsuchizaki, T. 1995. Complete sequence of an infectious full-length cDNA clone of citrus tatter leaf capillovirus: Comparative sequence analysis of capillovirus genomes. J. Gen. Virol. 76:2305-2309.

20. Saitou, N., and Nei, M. 1987. The neighbor-joining method: A new method for reconstructing phylogenetic trees. Mol. Biol. Evol. 4:406-425.

21. Sanger, F., Nicklen, S., and Coulson, A. R. 1977. DNA sequencing with chain-terminating inhibitors. Proc. Natl. Acad. Sci. USA 73:5463-5467.

22. Sawamura, K., Yamashita, K., and Arai, M. 1988. An apple stem grooving virus strain isolated from European pear (Pyrus communis). Bull. Fac. Agric. Hirosaki Univ. 50:22-26.

23. Semancik, J. S., and Weathers, L. G. 1965. Partial purification of mechanically transmissible virus associated with tatter leaf of citrus. Phytopathology 55:1354-1358.

24. Takahashi, T., Saito, N., Goto, M., Kawai, A., Namba, S., and Yamashita, S. 1990. Apple stem grooving virus isolated from Japanese apricot (Prunus mume) imported from China. Res. Bull. Plant Prot. Ser. Jpn. 26:15-21.

25. Thompson, J. D., Higgins, D. G., and Gibson, T. J. 1994. CLUSTAL W: Improving the sensitivity of progressive multiple sequence alignment through sequence weighting, position-specific gap penalties and weight matrix choice. Nucleic Acids Res. 22:4673-4680.

26. Verwoerd, T. C., Dekker, B. M. M., and Hoekema, A. 1989. A small-scale procedure for the rapid isolation of plant RNAs. Nucleic Acids Res. 17:2362.

27. Yanase, H. 1974. Studies on apple latent viruses in Japan. Pages 47-109 in: Bull. Fruit Tree Res. Stn. Jpn. Ser. C1.

28. Yoshikawa, N., Imaizumi, M., Takahashi, T., and Inouye, N. 1993. Striking similarities between the nucleotide sequence and genome organization of citrus tatter leaf and apple stem grooving capilloviruses. J. Gen. Virol. 74:2743-2747.

29. Yoshikawa, N., Sasaki, E., Kato, M., and Takahashi, T. 1992. The nucleotide sequence of apple stem grooving capillovirus genome. Virology 191:98-105.

30. Yoshikawa, N., Sasamoto, K., Sakurada, M., Takahashi, T., and Yanase, H. 1996. Apple stem grooving and citrus tatter leaf capilloviruses obtained from a single shoot of Japanese Pear (Pyrus serotina). Ann. Phytopathol. Soc. Jpn. 62:119-124.

31. Yoshikawa, N., and Takahashi, T. 1988. Properties of RNAs and proteins of apple stem grooving and apple chlorotic leaf spot viruses. J. Gen. Virol. 69:241-245. 